\title{
Tellurite-reduction-based assay for screening potential antibiotics
}

The occurrence of antibiotic-resistant bacteria represents a problem in the treatment of bacterial diseases. New antibiotics are being developed to treat patients infected with multi-resistant bacteria. The monitoring of the killing and/or inhibitory effect of potential antibiotics on the growth of bacteria is currently based on fluorogenic substrates, fluorescent dyes and expensive instrumentation. The antimicrobial effect of newly synthesized potential antibiotics is also examined using microtitre plates carrying bacterial cultures (Huigens et al., 2010). No growth of bacteria in the presence of the tested potential antibiotic is considered as a marker of its efficiency. Viable cell suspensions of bacteria have been described to reduce tellurite and turn grey/black regardless of whether they are tellurite resistant (Lloyd-Jones et al., 1991, 1994). We have developed a user-friendly assay for screening the susceptibility of bacteria to antibiotics. The assay is based on reduction of the potassium tellurite in metabolically active cells.

Uropathogenic Escherichia coli KL53 (Burian et al., 1990) bearing pTE53 plasmid conferring tellurite resistance, tellurite non-resistant E. coli MC4100 and Bacillus subtilis PY79 strains were used as test organisms for assessing antibiotic activity. All bacterial strains were grown in Luria-Bertani medium (Ausubel et al., 1987). Cell suspensions grown to an $\mathrm{OD}_{600}$ of 0.3 were transferred into a 96-well microplate in a volume of $200 \mu \mathrm{l}$, and successively cultivated for $12 \mathrm{~h}$ in the presence or absence of ampicillin $(50 \mu \mathrm{g}$ $\left.\mathrm{ml}^{-1}\right)$, chloramphenicol $\left(34 \mu \mathrm{g} \mathrm{ml}^{-1}\right)$, kanamycin $\left(30 \mu \mathrm{g} \mathrm{ml}^{-1}\right)$ and ciprofloxacin $\left(10 \mu \mathrm{g} \mathrm{ml}^{-1}\right)$. Potassium tellurite was added to final concentration $1 \mathrm{mM}$ to all wells to allow visualization of the activity of the antibiotics. Samples were incubated with potassium tellurite for $4 \mathrm{~h}$ at $37{ }^{\circ} \mathrm{C}$. The reduction of tellurite was determined by observing the difference in blackness (tellurite is reduced to black elemental tellurium) between cultures grown in the presence or absence of antibiotics. Cells turned black in the absence of antibiotics. However, we detected a significantly decreased reduction of tellurite in cell suspensions treated with kanamycin, chloramphenicol and ciprofloxacin in comparison to cell cultures grown in the absence of antibiotics (Fig. 1). No tellurite reduction was observed in ampicillintreated cultures of E. coli MC4100 (Fig. 1a) and B. subtilis (Fig. 1c). Ampicillinresistant E. coli KL53 reduced tellurite equally in the absence and presence of ampicillin (Fig. 1b). Ampicillin caused lysis of E. coli MC4100 and B. subtilis bacterial suspensions after $12 \mathrm{~h}$ of incubation at $37{ }^{\circ} \mathrm{C}$. We did not observe lysis of any of the tested bacterial suspensions in the presence of kanamycin, chloramphenicol and ciprofloxacin. However, the activity of kanamycin, chloramphenicol and ciprofloxacin was detectable by the decrease in the reduction of tellurite (Fig. 1a, b, c). No lysis of bacteria or a relatively slow onset of inhibition of bacterial growth prevents determination of the antimicrobial effect of a potential antibiotic using turbidity-based assays.

We have compared the sensitivity of tested strains to antibiotics using alamar blue and tellurite reduction assays. The alamar blue assay was performed according to the manufacturer's instructions (Invitrogen), and is based on reduction of the blue substrate to its pink (reduced) form by viable micro-organisms (Fields \& Lancaster, 1993). The reduced form of alamar blue is quantified using a fluorescence/absorbance reader. We used serial twofold dilutions of ampicillin, kanamycin, chloramphenicol, ciprofloxacin and tetracycline, and tested the sensitivity of E. coli KL53 and MC4100 to these antibiotics. ImageJ software (http:// rsb.info.nih.gov/ij) analysis of an image of the microtitre plate was used for quantification of the blackness of samples from the strains examined by the tellurite reduction assay (Fig. 2a, c). Fluorescence readings of the microtitre plate, obtained with a Tecan Safire2 microplate reader, were used for quantification of alamar blue reduction (Fig. 2b, d). Results were normalized to a positive control represented by cells incubated in absence of antibiotics. Blackness/fluorescence signal intensities were expressed as a percentage of the signal of the positive control incubated in absence of antibiotics. We observed a matching pattern between the efficiency of reduction of alamar blue and potassium tellurite by E. coli KL53 (Fig. 2a, b). The tellurite reduction assay performed as accurately as the alamar blue method. However, the (a)

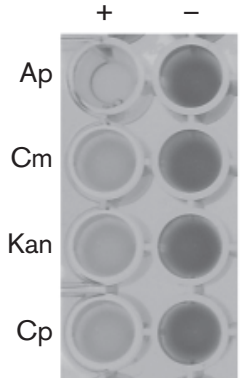

(b)

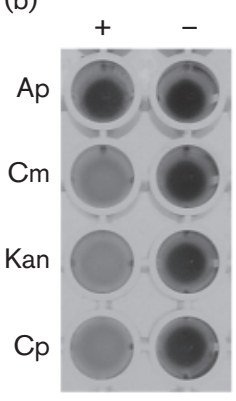

(c)

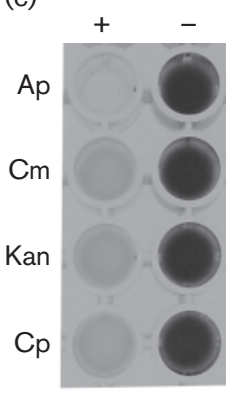

Fig. 1. Detection of the antibiotic susceptibility of bacterial cultures using tellurite reduction in the presence or absence of ampicillin (Ap), chloramphenicol $(\mathrm{Cm})$, kanamycin (Kan) and ciprofloxacin ( $\mathrm{Cp}$ ). The ability of the following bacterial strains to reduce tellurite to black elemental tellurium is shown: (a) E. coli MC4100, (b) E. coli KL53 and (c) B. subtilis PY79. The blackness of cells incubated in presence $(+)$ and absence $(-)$ of antibiotics is shown in the left and right columns, respectively. 


\section{E. coli KL53}

(a)

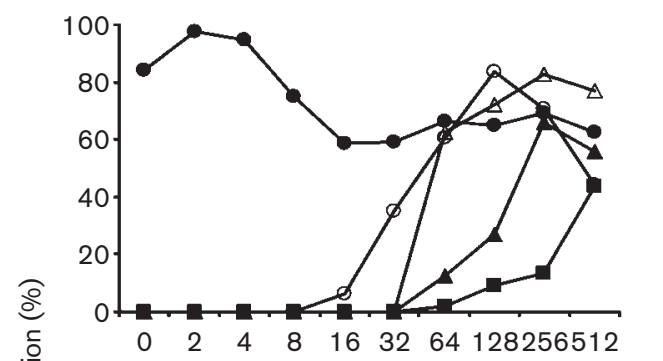

(b)

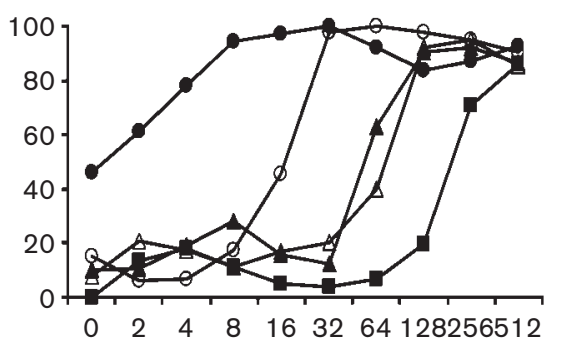

E. coli MC4100

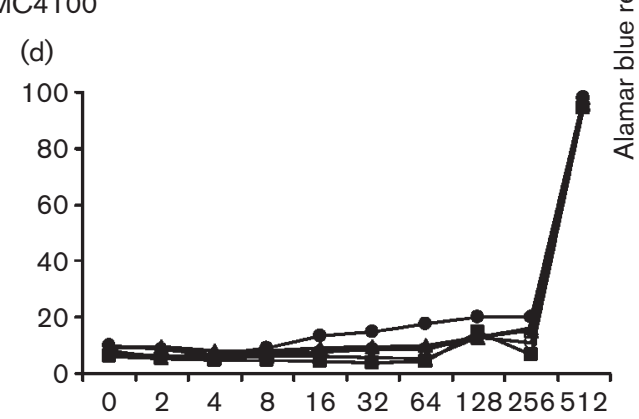

Antibiotic dilution

Fig. 2. Viability of $E$. coli KL53 and MC4100 examined by alamar blue ( $b$ and d) and tellurite reduction assays ( $a$ and $c)$. The starting concentrations of antibiotics were as follows: ampicillin $\left(\bullet, 500 \mu \mathrm{g} \mathrm{ml}^{-1}\right)$, kanamycin $\left(\bigcirc, 300 \mu \mathrm{g} \mathrm{ml}^{-1}\right)$, ciprofloxacin $\left(\boldsymbol{\square}, 100 \mu \mathrm{g} \mathrm{ml}^{-1}\right)$, chloramphenicol $\left(\triangle, 150 \mu \mathrm{g} \mathrm{ml}^{-1}\right)$ and tetracycline $\left(\boldsymbol{\Lambda}, 200 \mu \mathrm{g} \mathrm{ml}^{-1}\right)$.

variations in the purple coloration of the reduced form of alamar blue, although visible by eye, could not be quantified by software analysis of an image of microplate wells. The difference between blue/pink/ colourless is difficult to quantify by software analysis of such an image. Thus, a fluorescent reader is required for quantification of the alamar blue reduction.

Alamar blue and tellurite were reduced by E. coli MC4100 at a 512-fold dilution of antibiotics (Fig. 2c, d). The reduction efficiency of tellurite at this 512-fold dilution varied from 40 to $90 \%$ (Fig. 2c) and alamar blue reduction reached a maximum at the same dilution. However, E. coli MC4100 incubated in the absence of antibiotics reduced both substrates. The capability of alamar blue and tellurite reduction may be dependent on the type of bacterial strain.

Use of a tellurite-based assay for tests of bacterial susceptibility to potential antibiotics does not require expensive chemistry and instrumentation such as a fluorescence/absorbance reader. In summary, we have developed a tellurite-based colorimetric assay that provides reliable, rapid and inexpensive screening of the antibacterial effect of potential antibiotics on the growth of bacteria. The tellurite reduction assay may help to overcome limitations pertaining to drug susceptibility methods based on measurements of turbidity, optical density, absorbance and fluorescence.

\section{Acknowledgements}

This work was supported by a Biorekprot grant (ITMS 26240220048) supported by the Research and Development Operational Programme funded by the ERDF.

\section{Dušan Blaškovič and Ján Turňa}

Department of Molecular Biology, Comenius University, Mlynská Dolina B2122, 84215 Bratislava, Slovak Republic

Correspondence: Dušan Blaškovič (blaskovic@fns.uniba.sk)
Ausubel, F. M., Brent, R., Kingston, R. E., Moore, D. O., Seidman, J. S., Smith, J. A. \& Struhl, K. (1987). Current Protocols in Molecular Biology. New York: Wiley.

Burian, J., Beňo, J., Mačor, M., Guller, L. \& Siekel, P. (1990). Inducible resistance to tellurite in a human isolate of Escherichia coli. Biologia 45, 1021-1026.

Fields, R. D. \& Lancaster, M. V. (1993). Dualattribute continuous monitoring of cell proliferation/cytotoxicity. Am Biotechnol Lab 11, 48-50.

Huigens, R. W., III, Reyes, S., Reed, C. S., Bunders, C., Rogers, S. A., Steinhauer, A. T. \& Melander, C. (2010). The chemical synthesis and antibiotic activity of a diverse library of 2aminobenzimidazole small molecules against MRSA and multidrug-resistant A. baumannii. Bioorg Med Chem 18, 663-674.

Lloyd-Jones, G., Ritchie, D. A. \& Strike, P. (1991). Biochemical and biophysical analysis of plasmid pMJ600-encoded tellurite $\left[\mathrm{TeO}_{2}{ }^{(3-)}\right]$ resistance. FEMS Microbiol Lett 65, 19-24.

Lloyd-Jones, G., Osborn, A. M., Ritchie, D. A., Strike, P., Hobman, J. L., Brown, N. L. \& Rouch, D. A. (1994). Accumulation and intracellular fate of tellurite in tellurite-resistant Escherichia coli: a model for the mechanism of resistance. FEMS Microbiol Lett 118, 113-119. 